\title{
Hypertension care cascade in the Ingwavuma rural community, uMkhanyakude Health District, KwaZulu-Natal - South Africa
}

\author{
Herbert Chikafu ${ }^{\text {Corresp., } 1}$, Moses Chimbari ${ }^{1}$ \\ ${ }^{1}$ School of Nursing and Public Health, University of KwaZulu-Natal, Durban, KwaZulu-Natal, South Africa \\ Corresponding Author: Herbert Chikafu \\ Email address: chikafuh@gmail.com
}

Background. Treatment and control of hypertension are associated with a substantial reduction in adverse cardiovascular disease outcomes. Although South Africa aims to reduce the burden of cardiovascular diseases, there is limited evidence on the hypertension care cascade (HCC) performance in rural areas where stroke and hypertension are high. This study estimated HCC performance and identified predictors of hypertension screening among adults in the Ingwavuma community of KwaZuluNatal, South Africa.

Methods. This was a cross-sectional study. Data were collected using the WHO STEPwise approach to surveillance (STEPS) questionnaire from 400 adult participants, excluding pregnant women and those with physical or cognitive impairments. Three hundred and ninety-three participants had complete data, and 131 had high blood pressure. We calculated progression rates for screening, diagnosis, treatment and control of hypertension from the sub-sample of participants with high blood pressure and assessed the bivariate association between HCC stages and participant characteristics and their effect sizes. We used binary and multivariable logistic regression to identify predictors of hypertension screening.

Results. Eighty-eight per cent of participants reported prior screening for hypertension. However, only $53.5 \%$ of patients under pharmacological treatment for hypertension had controlled blood pressure. In bivariate regression, employed participants were $80.3 \%$ (COR $=0.197,95 \% \mathrm{Cl}[0.042-0.921]$ ) more likely to be screened. In multivariable regression, the likelihood of hypertension screening was $82.4 \%$ ( $A O R=$ $0.176,95 \% \mathrm{Cl}[0.047-0.655])$ lower among participants in a cohabiting union than single participants. Similarly, employed participants were $87.4 \%$ ( $\mathrm{AOR}=0.129,95 \% \mathrm{Cl}$ [0.017-0.952]) less likely to be screened than their unemployed counterparts.

Conclusions. The considerable attrition from the HCC across socio-demographic categories indicates a need for community-wide interventions. Empowering health care workers for community-based health promotion and hypertension management through point-of-care diagnostic tools could improve HCC performance. Efforts to improve the HCC should also focus on social determinants of health, notably gender and formal educational attainment. 
1 Hypertension Care Cascade in the Ingwavuma Rural Community, 2 uMkhanyakude Health District, KwaZulu-Natal - South Africa

3

4

5

6

7

8

9

10

11

12

13

14

15

16

17

18

19

20

21

22

23

24

25

26

27

28

29

30

31

32

33

34

35

36

37

38

39

Herbert Chikafu ${ }^{1}$, Moses John Chimbari ${ }^{1}$

${ }^{1}$ School of Nursing and Public Health, University of KwaZulu-Natal, Durban, KwaZulu-Natal, South Africa

Corresponding Author: Herbert Chikafu ${ }^{1}$

238 Mazisi Kunene Road, Durban, KwaZulu-Natal, 4001, South Africa

Email address: chikafuh@gmail.com

\section{Abstract}

Background. Treatment and control of hypertension are associated with a substantial reduction in adverse cardiovascular disease outcomes. Although South Africa aims to reduce the burden of cardiovascular diseases, there is limited evidence on the hypertension care cascade (HCC) performance in rural areas where stroke and hypertension are high. This study estimated HCC performance and identified predictors of hypertension screening among adults in the Ingwavuma community of KwaZulu-Natal, South Africa.

Methods. This was a cross-sectional study. Data were collected using the WHO STEPwise approach to surveillance (STEPS) questionnaire from 400 adult participants, excluding pregnant women and those with physical or cognitive impairments. Three hundred and ninety-three participants had complete data, and 131 had high blood pressure. We calculated progression rates for screening, diagnosis, treatment and control of hypertension from the sub-sample of participants with high blood pressure and assessed the bivariate association between HCC stages and participant characteristics and their effect sizes. We used binary and multivariable logistic regression to identify predictors of hypertension screening.

Results. Eighty-eight per cent of participants reported prior screening for hypertension. However, only $53.5 \%$ of patients under pharmacological treatment for hypertension had controlled blood pressure. In bivariate regression, employed participants were $80.3 \%$ (COR $=$ $0.197,95 \%$ CI [0.042-0.921]) more likely to be screened. In multivariable regression, the likelihood of hypertension screening was $82.4 \%(\mathrm{AOR}=0.176,95 \% \mathrm{CI}$ [0.047-0.655]) lower among participants in a cohabiting union than single participants. Similarly, employed participants were $87.4 \%$ ( $\mathrm{AOR}=0.129,95 \% \mathrm{CI}[0.017-0.952]$ ) less likely to be screened than their unemployed counterparts.

Conclusions. The considerable attrition from the HCC across socio-demographic categories indicates a need for community-wide interventions. Empowering health care workers for community-based health promotion and hypertension management through point-of-care 
40 diagnostic tools could improve HCC performance. Efforts to improve the HCC should also focus

41 on social determinants of health, notably gender and formal educational attainment.

42

43

44

45

46

47

48

49

50

51

52

53

54

55

56

57

58

59

60

61

62

63

64

65

66

67

68

69

70

71

72

73

74

75

76

77

78

79

Keywords: Chronic disease management, Control, Health promotion, Hypertension care cascade, Primary health, Social determinants, Rural KwaZulu-Natal

\section{Introduction}

The burden of disease in Sub-Saharan Africa and other low-to-middle income regions is shifting from communicable diseases to chronic noncommunicable diseases, and cardiovascular diseases cause substantial disability and premature death (WHO 2014). Hypertension which is most prevalent in Africa is a major risk factor for cardiovascular diseases (WHO 2019). Poor outcomes for COVID-19 for patients with hypertension, among other comorbidities, further highlight the importance of hypertension management. In a growing body of evidence, higher COVID-19 fatality was reported among patients with hypertension in a global systematic review (Ssentongo et al. 2020) and cohort study conducted in the Western Cape Province of South Africa (Boulle et al. 2020). Consequently, people with cardiovascular diseases and other chronic comorbidities have been listed among the prioritised groups in the COVID-19 vaccination program in South Africa (Agency 2021).

Hypertension management improves cardiovascular disease outcomes (Neal et al. 2000). However, management of hypertension is contingent on an effective hypertension care cascade (HCC) consisting of connected stages of screening, diagnosis, treatment and control. Care cascades for chronic conditions ensure timely intervention, consolidation of health gains and progression for further care where required (Perlman et al. 2016). Despite the significance of continuum of care, studies conducted in sub-Saharan Africa reported significant attrition out of the hypertension care cascade (Gómez-Olivé et al. 2017; Ware et al. 2019). Considerable spatial and socio-demographic variation in hypertension screening, awareness, treatment, and control in sub-Saharan Africa has been noted with poor outcomes in rural areas and among younger age groups (Chow et al. 2013; Kayima et al. 2013; Lloyd-Sherlock et al. 2014; Price et al. 2018). Progression through the HCC has been shown to be inversely associated with formal education, and females have a better awareness of their diagnosis, treatment, and control of hypertension than males (Adeloye \& Basquill 2014; Chow et al. 2013; Gomez-Olive et al. 2013; Jardim et al. 2017; Kayima et al. 2013). These care gaps in Africa have been attributed to health system deficiencies in most African countries (Ibrahim \& Damasceno 2012).

The suboptimal HCC performance in South Africa and other sub-Sahara African countries where improving life expectancy increases the population predisposed to metabolic-related diseases is worrisome given prevailing poor and pro-urban cardiovascular disease-related healthcare distribution (Chikafu \& Chimbari 2019; Maredza et al. 2016). Updated evidence on HCC performance is vital for timely health system interventions to avert avoidable fatal cardiovascular disease-related outcomes in rural areas with fewer or no tertiary health facilities. We, therefore, conducted this study in the Ingwavuma rural community in uMkhanyakude 
80

81

82

83

84

85

86

87

88

89

90

91

92

93

94

95

96

97

98

99

100

101

102

103

104

105

106

107

108

109

110

111

112

113

114

115

116

117

118

119

district of KwaZulu-Natal with three objectives: (a) to assess levels and gaps in the hypertension care cascade, (b) to assess whether a relationship exists between participant characteristics and HCC outcomes, and (c) to determine predictors of hypertension screening.

\section{Materials \& Methods}

\section{Setting}

We conducted this study in Ingwavuma, a rural community under Jozini Local Municipality in uMkhanyakude district Municipality of KwaZulu-Natal, South Africa. KwaZulu-Natal is the second-most populous province in South Africa and, notwithstanding inter-district variation, has the highest proportion of poor rural households and high unemployment levels (Release \& P 2019; Stats 2018). Although healthcare services are publicly provided, transport costs hinder the utilisation of healthcare services in rural KwaZulu-Natal (Chimbindi et al. 2015).

UMkhanyakude district has a high prevalence of communicable and noncommunicable diseases (Sharman \& Bachmann 2019; Wong et al. 2021), and in mid-2021, it was among the districts with the least cumulative cases (11 548) and fatalities (422) of COVID-19 in KwaZulu-Natal province (KZN_Department_of_Health 2021).

The Ingwavuma community is located along South Africa's border with Eswatini and Mozambique (Figure 1), is semiarid and inhabited by IsiZulu and Swati speaking people under traditional leadership. Less than half of the study area population had attained secondary education, and most were unemployed (Chikafu \& Chimbari 2020). Formal healthcare services in rural Ingwavuma are largely publicly provided through 11 primary clinics within a $60 \mathrm{~km}$ radius of a referral district hospital that provides tertiary care. Patients access essential drugs freely at local clinics and monthly mobile clinics. Community health workers (CHW) trained in basic primary healthcare coordinate primary health needs in their communities. However, access to health centres is sometimes hindered by the long distances that the patients have to travel.

\section{Study design and participants}

This was a cross-sectional, observational and analytical study. We determined a sample size of 384 participants through the Cochran formula for populations with unknown disease prevalence (Israel 1992) and used a multistage sampling approach with a combination of convenience and random sampling (Figure 2). Convenience sampling was used in the first stage to select the study area comprising three main villages that cover a considerable territory of the Ingwavuma community. The villages constitute three adjoining municipal wards $(13,16$, and 17) of the Jozini local municipality. The decision to conduct the study in Ingwavuma was on the basis that the larger project in whose context the current study was conducted was situated in that area. In the second stage, two community health blocks were randomly chosen in each village. A community health block comprised of households served by a CHW. Households were then selected in stage three from a household listing of each block using systematic random sampling. After identifying a starting household picked from an online random number generator (Generator), we selected households with a sampling interval of one household. Households 
120 were selected only once, and a maximum of two adult participants ( $>=18$ years) enrolled from

121

122

123

124

125

126

127

128

129

130

131

132

133

134

135

136

137

138

139

140

141

142

143

144

145

146

147

148

149

150

151

152

153

154

155

156

157

158

159

selected households after obtaining permission from the household head or their proxy to enrol the household. We used the lottery method for households with more than two consenting participants with separate ballots for females and males. Only usual residents were considered in the study to ensure that findings were representative of the Ingwavuma community. The following groups were also excluded on ethical considerations or inability to attend measurement clinics: the physically and cognitively impaired, acutely ill and the aged. Pregnant women were not enrolled, considering the high likelihood of gestational induced hypertension and diabetes.

A total of 400 adults enrolled in the main study, and 393 participants had complete data. We analysed hypertension cascade progression from 131 adults diagnosed with hypertension out of the 393 participants. The sub-sample of 131 adults shown in Table 1 comprised 89 (67.9\%) females and $42(32.1 \%)$ males with a mean age of 56.5 years $(\mathrm{SD}=16.51)$. Over two fifths $(42.7 \%)$ were at least 60 years old, a quarter $(23.7 \%)$ had attained primary education, $55.7 \%$ reported to be single, and the majority (93.9\%) were unemployed.

\section{Study instrument and data collection}

We adapted the WHO STEPwise approach to surveillance (STEPS) questionnaire for this study (Organization 2010). The questionnaire was translated into isiZulu by a native speaker, reviewed for appropriateness and pilot-tested in a village with community research assistants (CRAs) fluent in the local dialect. Swati speaking individuals in the study area also speak isiZulu. The finalised isiZulu questionnaire had closed and open-ended questions that were grouped into the following five sections; (a) socio-demographic characteristics, (b) health awareness, (c) health knowledge, (d) healthcare utilisation, and (e) modifiable health behaviours was pre-tested in one of the sampled villages. Households that participated in the pre-test were excluded from the study.

Data were collected between Novemeber 2020 and February 2021 over two phases. In the first phase, we conducted a household survey to collect self-reported data on health status and modifiable health behaviours (alcohol consumption, perception of salt consumption, and physical activity) using the STEPS questionnaire. In the second phase, blood pressure, blood glucose and anthropometric measurements were collected from phase one participants by a trained nurse at suitable locations within sampled communities. Data were collected electronically using KoBo collect on Android devices (Initiative 2018) during both phases.

\section{Measurements and definitions}

Brachial blood pressure was measured using a validated and calibrated digital blood pressure monitor (OMRON M6; Omron Healthcare Co, Japan) with appropriate cuff sizes. We recorded three diastolic and systolic pressure readings spaced at least 5 minutes after a short rest upon arrival at the measurement centre following WHO guidelines on the general environment and sitting posture (WHO 2020). The second and third systolic and diastolic measurements were averaged to determine blood pressure status, and hypertension was defined as follows; a) either

Peer) reviewing PDF | (2021:05:60819:1:1:CHECK 2 Sep 2021) 
160

161

162

163

164

165

166

167

168

169

170

171

172

173

174

175

176

177

178

179

180

181

182

183

184

185

186

187

188

189

190

191

192

193

194

195

196

197

198

199

or both of systolic blood pressure of $\geq 140 \mathrm{mmHg}$, diastolic blood pressure of $\geq 90 \mathrm{mmHg}$ (25) or, b) current use or history of pharmacological treatment prescribed by a healthcare professional to control hypertension.

We measured glycated haemoglobin A1c (HbA1c) from blood drawn from the second or third finger using a validated and calibrated point-of-care machine (HemoCue $\mathrm{Hb} 501$, HemoCue, Sweden). The HbA1c test does not require fasting before an assessment and indicates mean blood glucose for a 2-to-3-month period preceding the test, and as such, it is ideal for screening undiagnosed patients and assessing blood sugar control for diagnosed patients. Diabetes mellitus status was classified as normal blood glucose (HbA1c; $<5.7 \%$ ), prediabetes (HbA1c; 5.7-6.4\%) and diabetes (HbA1c; $\geq 6.5 \%$ ) according to the WHO diagnostic criteria (WHO 2016). Participants who self-reported current treatment for diabetes mellitus were classified as diabetic irrespective of HbAlc level.

The following anthropometric measurements were made; weight in $\mathrm{kg}$ to the nearest $100 \mathrm{~g}$ and height in cm using a calibrated digital scale (SECA 763; GmbH \& Co. KG, Germany) fitted with a stadiometer. Participants wore light clothing, stood upright without shoes, facing horizontally forward and with feet and heels together, shoulders, head, and buttocks against the wall. Body mass index (BMI) was calculated and classified as underweight (BMI $<18 \mathrm{~kg} / \mathrm{m} 2$ ), normal weight $(18 \mathrm{~kg} / \mathrm{m} 2 \leq \mathrm{BMI}<25 \mathrm{~kg} / \mathrm{m} 2)$; overweight $(25 \mathrm{~kg} / \mathrm{m} 2 \leq \mathrm{BMI}<30 \mathrm{~kg} / \mathrm{m} 2)$; and obese (BMI $\geq 30 \mathrm{~kg} / \mathrm{m} 2)$.

Participants also provided information on modifiable health behaviours. Physical activity (PA) level was determined from self-reported data on the type, intensity (moderate or vigorous) and duration (in hours and minutes) of physical activities during a typical week. Weekly estimates of physical activity were expressed in moderate-intensity minutes (1 vigorous-intensity minute $=2$ moderate-intensity minutes) and categorised as insufficient (PA $<150$ minutes), sufficient (150 $\leq \mathrm{PA}<300$ minutes), and high ( $\mathrm{PA} \geq 300$ minutes). Self-reported alcohol consumption and tobacco smoking in the month preceding the survey were used to define current alcohol consumption and tobacco smoking status.

\section{Outcome variables}

The four stages of the HCC (see Figure 3) were the outcome variables of the study. The care cascade depicts the progression in hypertension management. Participants were deemed screened if they ever had their blood pressure checked and classified as aware if they were diagnosed with hypertension and informed of their status by a health professional. Treatment was defined as the current use of antihypertensive medication prescribed by a healthcare worker to manage blood pressure, while control was defined as systolic blood pressure $<140 \mathrm{mmHg}$ and diastolic blood pressure $<90 \mathrm{mmHg}$ on the testing day for participants under treatment.

\section{Statistical analysis}

Data were analysed using IBM SPSS Statistics version 26 for Windows (IBM Corp., Armonk, NY, USA). Firstly, we assessed the prevalence levels of screening, awareness, treatment, and 
200 control. Hypertension care cascade performance was expressed in absolute and relative terms. 201 Absolute progression rate was defined as the proportion of the 131 hypertensive participants 202 achieving each level of the HCC while relative progression was expressed as the ratio of 203 hypertensive participants attaining each level of the HCC relative to the preceding level. 204 Secondly, the association between HCC stages and categorical factors was assessed using the 205 chi-square test or Fisher's exact test, where applicable. We also obtained effect sizes to ascertain 206 the strength of association and applied the Bonferroni and Holm-Bonferroni correction to correct 207 for type 1 error risk. Thirdly, we conducted unadjusted and adjusted binary logistic regression 208 analyses to determine the predictors of hypertension screening. Finally, we ran age-stratified 209 logistic regressions to assess potential effect modifiers. Univariate regression results are presented as 210 crude odds ratios (COR) and their 95\% confidence intervals (95\% CI), while multivariate 211 regression results are presented as adjusted odds ratios (AOR) and 95\% CIs. Statistical 212 significance was set at $\mathrm{p}<0.05$ for all analyses.

213

214

\section{Ethical considerations}

216

217

\section{Results}

\section{Levels of screening, awareness, treatment, and control of hypertension}

220

221

222

223

224

225

226

227

228

229

230

231

232

233

234

235

236

237

238

239

Attrition across the hypertension care cascade is noticeable in Ingwavuma. The number of participants progressing through the HCC levels are presented in figure 4 and expressed as percentages of the cohort in figure 5. Out of the 131 participants diagnosed with hypertension, $115(88 \%)$ were screened, $81(70 \%)$ were diagnosed, $71(63 \%)$ were receiving treatment, and 33 (30\%) had controlled blood pressure. In absolute HCC analysis, the least gap was observed between diagnosis and treatment, while the largest cascade gap was observed between treatment and control. However, relative progression rates were marginally higher, indicating treatment coverage of $87.7 \%$ among diagnosed participants and controlled blood pressure in half (53.5\%) of patients receiving pharmacological treatment (Figure 6).

Table 2 presents HCC attainment levels across socio-demographic categories. The coverage of hypertension screening was at least $80 \%$ for all categories except for the $18-39$ years (73.8\%), post-primary education $(72.7 \%)$ and employed (62.5\%) categories. However, the prevalence of screening only differed significantly with employment status $\left(\chi^{2}=0.024\right.$, d.f $\left.=1\right)$, albeit with a small effect size (Cramer's $V=0.197)$. Further, there were comparable levels of awareness between females (71.3\%) and males (68.6\%); and an unexpectedly non-significant negative gradient between formal education and awareness. Awareness on hypertension status varied significantly with BMI $\left(\chi^{2}=0.006\right.$, d.f $\left.=2\right)$ albeit with small effect size (Cramer's V = $0.280)$. The Holm-Bonferroni correction $(p<0.008)$ indicated that overweight $(\mathrm{p}=0.005)$ and obesity ( $p=0.002)$ were associated with higher awareness. It is noteworthy that treatment coverage and control were not significantly associated with any predictor. However, control of

Peer) reviewing PDF | (2021:05:60819:1:1:CHECK 2 Sep 2021) 
240 blood pressure was higher among females (53.1\%) than males (35.0\%) and least (38.2\%) among 241 participants aged 60 years and above.

242

243 Factors associated with screening for hypertension

244 Binary logistic regression showed that employment status was the only significant predictor of

245 hypertension screening in the unadjusted analysis (Table 3). Compared with unemployed

246 participants, being employed was associated with an 80.3\% lower likelihood (COR $=0.197,95 \%$

247 CI [0.042-0.921]) of being screened. In the adjusted regression model, employed participants

248 remained less likely $(\mathrm{AOR}=0.129,95 \% \mathrm{CI}[0.017-0.952])$ to be screened relative to their

249 unemployed counterparts. Although marital status was not a significant predictor of hypertension

250 screening in the bivariate model, results showed that participants in a cohabiting union were $25182.4 \%(\mathrm{AOR}=0.176,95 \% \mathrm{CI}[0.047-0.655])$ less likely to have been screened compared with 252 participants who reported to be single. In stratified regression to assess potential effect modifiers, 253 marital status was a significant predictor among females only (Table 4). Females in a cohabiting 254 union were $99 \%(\mathrm{AOR}=0.011$ [0.000-0.325]) less likely to be screened when compared with 255 females who had never been in a marital union.

256

257 Discussion

258 This study assessed the hypertension care cascade in the Ingwavuma rural community in north259 eastern KwaZulu-Natal, South Africa. An effective hypertension care cascade is essential for 260 early detection and management of hypertension, a major cardiovascular disease risk factor. In 261 the backdrop of the high burden of stroke in rural South Africa (Maredza et al. 2016), efficient 262 hypertension management could reduce the financial burden on households and the public 263 healthcare system by minimising the often lengthy and costly tertiary care associated with 264 cardiovascular disease complications.

265 Our study noted attrition at all stages of the HCC. The gaps in diagnosis, treatment and 266 control are consistent with studies conducted in rural South Africa (Addo et al. 2007; Adeniyi et 267 al. 2016; Siedner et al. 2018; Wong et al. 2021). Hypertension care cascade gaps in South Africa 268 have been attributed to long distances to health centres, poor health-seeking behaviour and 269 perceived low quality of services, including lengthy waiting periods (Nulu et al. 2016). However, 270 a portion of the gap between diagnosis and treatment in our study may not wholly indicate HCC 271 failure but could also be attributed to the prescription of lifestyle modification. Lifestyle 272 interventions including weight reduction, healthy diet, physical activity and reduced alcohol 273 consumption are efficacious for managing metabolic syndrome and accordingly, hypertension 274 management guidelines in South Africa recommend lifestyle modification as the sole therapy for 275 grade 1 hypertension (systolic BP; $140-159 \mathrm{mmHg}$ and diastolic BP; 90-99 $\mathrm{mmHg}$ ) for up to 6 276 months and as a complementary therapy for higher grades of hypertension (Seedat et al. 2014). 277 Thus, the gap between diagnosis and treatment may result from participants with elevated blood 278 pressure under non-pharmacological treatment. 
279

280

281

282

283

284

285

286

287

288

289

290

291

292

293

294

295

296

297

298

299

300

301

302

303

304

305

306

307

308

309

310

311

312

313

314

315

316

317

Although relatively higher than levels found in other rural areas in national studies (Berry et al. 2017; Ware et al. 2019), the low level of controlled hypertension in Ingwavuma is a concern. In South Africa, where most households depend on publicly provided healthcare, it is crucial to improve the level of controlled hypertension to minimise avoidable expenditure to enhance the country's expenditure efficiency of the constrained public health financing and improve the poor HCC outcomes relative to national income (Geldsetzer et al. 2019).

Social determinants of health explain most health differentials in South Africa (Ataguba et al. 2015). Health awareness and outcomes are poor in communities with low socioeconomic status, particularly in rural and poor communities where formal education attainment is low. Contrary to earlier studies conducted in South Africa and other African countries (Adeniyi et al. 2016; Chow et al. 2013; Siedner et al. 2018), our study did not find notable differences between unadjusted and adjusted analyses on most socio-demographic predictors of hypertension screening except gender. The non-significance of most social determinants of health suggest the need for community-wide interventions to promote overall health-seeking and HCC progression. There is also a need for complementary structural measures to address differentials in HCC progression. Low healthcare utilisation rates for noncommunicable diseases in rural areas has been attributed to the predominance of primary healthcare services concentrated on maternal health, child health and communicable disease management (Geldsetzer et al. 2019). Because of the chronic noncommunicable disease burden, it is necessary to promote primary healthcare beyond maternal health, child health and communicable disease control. Furthermore, health promotion interventions could be used to influence health perceptions and awareness to shift the utilisation of chronic healthcare services, including hypertension management from reactive utilisation toward proactive health-seeking.

Interventions to improve HCC outcomes should also focus on the social determinants of health to influence health-seeking behaviours, particularly gender. The better HCC performance among females observed in overall and sex-stratified analysis corroborates findings from national-level surveys (Lloyd-Sherlock et al. 2014; Peltzer \& Phaswana-Mafuya 2013; Steyn et al. 2008) and is consistent with findings from studies conducted in rural municipalities in northeastern South Africa (Gomez-Olive et al. 2013; Jardim et al. 2017) and other sub-Saharan African countries (Gómez-Olivé et al. 2017; Kayima et al. 2013; Price et al. 2018). Adult females have higher odds of better HCC performance than males partly resulting from frequent contact with the healthcare system for maternal healthcare needs. The gap between males and females is also attributable to gendered household roles in rural areas where females attend to family health needs. Often, women accompany young and elderly patients to seek care and thus have more contact with the healthcare system. Therefore, all else remaining the same, women have a higher likelihood of being screened for hypertension and progress through the hypertension care cascade. On the other hand, cultural connotations of masculinity and power that were found to affect general health-seeking and HIV treatment among males in rural KwaZulu-Natal (Hunter 2003) potentially explain their poor performance on the HCC. 
318 Therefore, it is crucial to embed strategies to reshape gendered health-seeking perceptions 319 among males.

320

321

322

323

324

325

326

327

328

329

330

331

332

333

334

335

336

337

338

339

340

341

342

343

344

345

346

347

348

349

350

351

352

353

354

355

356

357

Implementation of primary healthcare reforms has the potential to improve $\mathrm{HCC}$ outcomes in Ingwavuma and other rural areas. The reach and scope of CHWs evolved considerably over the past century from limited roles as "Native Anti-Malaria Assistants" in selected regions (MacKinnon 2001) to the current Ward-based Primary Health Care Outreach Team (WBPHCOT) Strategy where they provide the last-mile delivery of primary health, including promoting treatment adherence for chronic conditions (Health 2018; Schneider et al. 2018). In addition to executing treatment adherence strategies towards attaining the WBPHCOT policy outcome of longevity and good health (Health 2018), there is a need to incorporate health promotion strategies to improve awareness of hypertension and its nexus with noncommunicable diseases in rural communities. Regional health promotion units could also provide CHWs with intelligible synthesised health system reports and research findings for appraisal with national and regional epidemiology patterns. Furthermore, local government and public health administrators should encourage researchers to undertake community engagement activities.

Advances in diagnostic technology provide opportunities to improve hypertension care cascade performance in rural areas. Given widespread white coat and masked hypertension in Africa (Noubiap et al. 2018), portable blood pressure monitors could be used for periodic homebased blood pressure screening and monitoring. Such community-based initiatives could help manage overcrowding at health facilities and allow physical distancing in line with COVID-19 protocols. They also improve access to care in areas where primary healthcare centres are distant. Similarly, given that mobile and internet connectivity is relatively good in South Africa, including our study area, SMS-text messaging and other mHealth innovations could be used to provide support and improve treatment adherence. A study conducted in South Africa demonstrated a positive effect of SMS-text messaging on hypertension treatment adherence (Leon et al. 2015). Furthermore, the community-based and eHealth initiatives could be integrated with geographic information systems to generate surveillance data for policymaking.

This study had some limitations. First, we used self-reported data that may have misestimated the prevalence of screening and diagnosis due to recall bias. Second, the study was cross-sectional, and as such, we could not infer causality. Third, we determined hypertension status from a single sitting due to resource constraints against the recommended three distinct moments in standard clinical diagnosis (Seedat et al. 2014). However, the study had noteworthy strengths. The major strength of this study is the generation of micro-level evidence on HCC performance from a large sample in a rural community characterised by low socioeconomic indicators and dominant traditional practices. Micro-level patterns in healthcare utilisation can be missed in large scale surveys. Also, excluding temporary residents from the study ensured that findings reflect HCC levels in the community. Participants who affirmed being on prescribed antihypertensive treatment during the household survey were requested to avail their medication packets for verification, and as such, our study provides a reliable estimate of hypertension control in the Ingwavuma community. Finally, the study site has socio-demographic similarities 
358

359

360

361

362

363

364

365

366

367

368

369

370

371

372

373

374

375

376

377

378

379

380

381

382

383

384

385

386

387

388

389

390

391

392

393

394

395

396

397

398

399

400

with other rural municipalities in the uMkhanyakude district municipality thus, our study findings are generalisable to the district level.

\section{Conclusions}

We conclude that there is a sub-optimal hypertension cascade of care in Ingwavuma, especially the low level of controlled hypertension for patients under treatment. The findings have implications on the government's commitment towards reducing the burden of noncommunicable diseases achievement of sustainable development goals and targets for noncommunicable diseases in the National Development Plan. Furthermore, improvements in the HCC are necessary for managing the COVID-19 pandemic. We recommend the following to improve the hypertension care cascade in rural KwaZulu-Natal where supply-side constraints and socioeconomic factors limit utilisation of healthcare services: a) skilling of community health workers to promote awareness on hypertension and chronic noncommunicable diseases, $b$ ) incorporation of hypertension management programs into the existing clinic and communitybased health promotion activities, c) adoption of point of care technology for community-based screening and monitoring of blood pressure, and d) adaption of eHealth and mHealth interventions to promote health awareness and treatment adherence.

Acknowledgements: Authors thank Ingwavuma community leaders and households for participating in this research. We are also grateful to Celiwe Tembe, Nozipho Mthembu, and Sinenhlanhla Mthembu for their meticulous work as Community Research Assistants. We acknowledge, with gratitude, TIBASA colleagues for their support.

\section{References}

Addo J, Smeeth L, and Leon DA. 2007. Hypertension in sub-saharan Africa: a systematic review. Hypertension 50:1012-1018. 10.1161/HYPERTENSIONAHA.107.093336

Adeloye D, and Basquill C. 2014. Estimating the prevalence and awareness rates of hypertension in Africa: a systematic analysis. PloS One 9:e104300. 10.1371/journal.pone.0104300

Adeniyi OV, Yogeswaran P, Longo-Mbenza B, and Ter Goon D. 2016. Uncontrolled Hypertension and Its Determinants in Patients with Concomitant Type 2 Diabetes Mellitus (T2DM) in Rural South Africa. PloS One 11:e0150033. 10.1371/journal.pone. 0150033

Agency SAGN. 2021. President outlines SA's COVID-19 vaccination programme. Available at https://www.sanews.gov.za/south-africa/president-outlines-sas-covid-19-vaccinationprogramme.

Ataguba JE, Day C, and McIntyre D. 2015. Explaining the role of the social determinants of health on health inequality in South Africa. Glob Health Action 8:28865. 10.3402/gha.v8.28865 
401

402

403

404

405

406

407

408

409

410

411

412

413

414

415

416

417

418

419

420

421

422

423

424

425

426

427

428

429

430

431

432

433

434

435

436

437

438

439

440

441

442

443

444

445

446

447

448

449

450

451
Berry KM, Parker W-a, Mchiza ZJ, Sewpaul R, Labadarios D, Rosen S, and Stokes A. 2017. Quantifying unmet need for hypertension care in South Africa through a care cascade: evidence from the SANHANES, 2011-2012. BMJ global health 2:e000348.

Boulle A, Davies MA, Hussey H, Ismail M, Morden E, Vundle Z, Zweigenthal V, Mahomed H, Paleker M, Pienaar D, Tembo Y, Lawrence C, Isaacs W, Mathema H, Allen D, Allie T, Bam JL, Buddiga K, Dane P, Heekes A, Matlapeng B, Mutemaringa T, Muzarabani L, Phelanyane F, Pienaar R, Rode C, Smith M, Tiffin N, Zinyakatira N, Cragg C, Marais F, Mudaly V, Voget J, Davids J, Roodt F, van Zyl Smit N, Vermeulen A, Adams K, Audley G, Bateman K, Beckwith P, Bernon M, Blom D, Boloko L, Botha J, Boutall A, Burmeister S, Cairncross L, Calligaro G, Coccia C, Corin C, Daroowala R, Dave JA, De Bruyn E, De Villiers M, Deetlefs M, Dlamini S, Du Toit T, Endres W, Europa T, Fieggan G, Figaji A, Frankenfeld P, Gatley E, Gina P, Govender E, Grobler R, Gule MV, Hanekom C, Held M, Heynes A, Hlatswayo S, Hodkinson B, Holtzhausen J, Hoosain S, Jacobs A, Kahn M, Kahn T, Khamajeet A, Khan J, Khan R, Khwitshana A, Knight L, Kooverjee S, Krogscheepers R, Jacque Kruger J, Kuhn S, Laubscher K, Lazarus J, Le Roux J, Lee Jones S, Levin D, Maartens G, Majola T, Manganyi R, Marais D, Marais S, Maritz F, Maughan D, Mazondwa S, Mbanga L, Mbatani N, Mbena B, Meintjes G, Mendelson M, Moller E, Moore A, Ndebele B, Nortje M, Ntusi N, Nyengane F, Ofoegbu C, Papavarnavas N, Peter J, Pickard H, Pluke K, Raubenheimer PJ, Robertson G, Rozmiarek J, Sayed A, Scriba M, Sekhukhune H, Singh P, Smith E, Soldati V, Stek C, van den Berg R, van der Merwe LR, Venter P, Vermooten B, Viljoen G, Viranna S, Vogel J, Vundla N, Wasserman S, Zitha E, Lomas-Marais V, Lombard A, Stuve K, Viljoen W, Basson V, Le Roux S, Linden-Mars E, Victor L, Wates M, Zwanepoel E, Ebrahim N, Lahri S, Mnguni A, Crede T, de Man M, Evans K, Hendrikse C, Naude J, Parak M, Szymanski P, Van Koningsbruggen C, Abrahams R, Allwood B, Botha C, Henndrik Botha M, Broadhurst A, Claasen D, Daniel C, Dawood R, du Preez M, Du Toit N, Erasmus K, Koegelenberg CFN, Gabriel S, Hugo S, Jardine T, Johannes C, Karamchand S, Lalla U, Langenegger E, Louw E, Mashigo B, Mhlana N, Mnqwazi C, Moodley A, Moodley D, Moolla S, Mowlana A, Nortje A, Olivier E, Parker A, Paulsen C, Prozesky H, Rood J, Sabela T, Schrueder N, Sithole N, Sithole S, Taljaard JJ, Titus G, Van Der Merwe T, van Schalkwyk M, Vazi L, Viljoen AJ, Yazied Chothia M, Naidoo V, Alan Wallis L, Abbass M, Arendse J, Armien R, Bailey R, Bello M, Carelse R, Forgus S, Kalawe N, Kariem S, Kotze M, Lucas J, McClaughlin J, Murie K, Najjaar L, Petersen L, Porter J, Shaw M, Stapar D, Williams M, Aldum L, Berkowitz N, Girran R, Lee K, Naidoo L, Neumuller C, Anderson K, Begg K, Boerlage L, Cornell M, de Waal R, Dudley L, English R, Euvrard J, Groenewald P, Jacob N, Jaspan H, Kalk E, Levitt N, Malaba T, Nyakato P, Patten G, Schneider H, Shung King M, Tsondai P, Van Duuren J, van Schaik N, Blumberg L, Cohen C, Govender N, Jassat W, Kufa T, McCarthy K, Morris L, Hsiao NY, Marais R, Ambler J, Ngwenya O, Osei-Yeboah R, Johnson L, Kassanjee R, and Tamuhla T. 2020. Risk factors for COVID-19 death in a population cohort study from the Western Cape Province, South Africa. Clinical Infectious Diseases:ciaa1198. $10.1093 / \mathrm{cid} /$ ciaa1198

Chikafu H, and Chimbari MJ. 2019. Cardiovascular Disease Healthcare Utilization in SubSaharan Africa: A Scoping Review. International Journal of Environmental Research and Public Health 16:419. 10.3390/ijerph16030419

Chikafu H, and Chimbari MJ. 2020. Levels and Correlates of Physical Activity in Rural Ingwavuma Community, uMkhanyakude District, KwaZulu-Natal, South Africa. International Journal of Environmental Research and Public Health 17:6739. 10.3390/ijerph17186739

Chimbindi N, Bor J, Newell ML, Tanser F, Baltussen R, Hontelez J, de Vlas SJ, Lurie M, Pillay D, and Barnighausen T. 2015. Time and Money: The True Costs of Health Care 
452

453

454

455

456

457

458

459

460

461

462

463

464

465

466

467

468

469

470

471

472

473

474

475

476

477

478

479

480

481

482

483

484

485

486

487

488

489

490

491

492

493

494

495

496

497

498

499

500

501

502
Utilization for Patients Receiving "Free" HIV/Tuberculosis Care and Treatment in Rural KwaZulu-Natal. Journal of Acquired Immune Deficiency Syndromes 70:e52-60. 10.1097/QAI.0000000000000728

Chow CK, Teo KK, Rangarajan S, Islam S, Gupta R, Avezum A, Bahonar A, Chifamba J, Dagenais G, Diaz R, Kazmi K, Lanas F, Wei L, Lopez-Jaramillo P, Fanghong L, Ismail $\mathrm{NH}$, Puoane T, Rosengren A, Szuba A, Temizhan A, Wielgosz A, Yusuf R, Yusufali A, McKee M, Liu L, Mony P, Yusuf S, and investigators PS. 2013. Prevalence, awareness, treatment, and control of hypertension in rural and urban communities in high-, middle-, and low-income countries. JAMA 310:959-968. 10.1001/jama.2013.184182

Geldsetzer P, Manne-Goehler J, Marcus ME, Ebert C, Zhumadilov Z, Wesseh CS, Tsabedze L, Supiyev A, Sturua L, Bahendeka SK, Sibai AM, Quesnel-Crooks S, Norov B, Mwangi KJ, Mwalim O, Wong-McClure R, Mayige MT, Martins JS, Lunet N, Labadarios D, Karki KB, Kagaruki GB, Jorgensen JMA, Hwalla NC, Houinato D, Houehanou C, Msaidie M, Guwatudde D, Gurung MS, Gathecha G, Dorobantu M, Damasceno A, Bovet P, Bicaba BW, Aryal KK, Andall-Brereton G, Agoudavi K, Stokes A, Davies JI, Barnighausen T, Atun R, Vollmer S, and Jaacks LM. 2019. The state of hypertension care in 44 lowincome and middle-income countries: a cross-sectional study of nationally representative individual-level data from 1.1 million adults. Lancet 394:652-662. 10.1016/S01406736(19)30955-9

Generator RI. Randomness and Integrity Services Ltd. URL: http://www random org/integers.

Gómez-Olivé FX, Ali SA, Made F, Kyobutungi C, Nonterah E, Micklesfield L, Alberts M, Boua R, Hazelhurst S, Debpuur C, Mashinya F, Dikotope S, Sorgho H, Cook I, Muthuri S, Soo C, Mukomana F, Agongo G, Wandabwa C, Afolabi S, Oduro A, Tinto H, Wagner RG, Haregu T, Wade A, Kahn K, Norris SA, Crowther NJ, Tollman S, Sankoh O, Ramsay M, Gen AWI, and the HAC. 2017. Regional and Sex Differences in the Prevalence and Awareness of Hypertension: An H3Africa AWI-Gen Study Across 6 Sites in Sub-Saharan Africa. Global heart 12:81-90. 10.1016/j.gheart.2017.01.007

Gomez-Olive FX, Thorogood M, Clark B, Kahn K, and Tollman S. 2013. Self-reported health and health care use in an ageing population in the Agincourt sub-district of rural South Africa. Global health action 6:19305.

Health NDo. 2018. Policy Framework and Strategy for Ward Based Primary Healthcare Outreach Teams 2018/19-2023/24. Department of Health Pretoria.

Hunter M. 2003. Masculinities and multiple-sexual-partners in KwaZulu-Natal: The Making and Unmaking of Isoka.

Ibrahim MM, and Damasceno A. 2012. Hypertension in developing countries. Lancet 380:611619. 10.1016/S0140-6736(12)60861-7

Initiative HH. 2018. KoBoToolbox: Data collection tools for challenging environments.

Israel GD. 1992. Determining sample size.

Jardim TV, Reiger S, Abrahams-Gessel S, Gomez-Olive FX, Wagner RG, Wade A, Barnighausen TW, Salomon J, Tollman S, and Gaziano TA. 2017. Hypertension management in a population of older adults in rural South Africa. Journal of Hypertension 35:1283-1289. 10.1097/HJH.0000000000001312

Kayima J, Wanyenze RK, Katamba A, Leontsini E, and Nuwaha F. 2013. Hypertension awareness, treatment and control in Africa: a systematic review. BMC Cardiovascular Disorders 13:54. 10.1186/1471-2261-13-54

KZN_Department_of_Health. 2021. COVID-19 STATISTICS IN KZN. Available at http://www.kznhealth.gov.za/coronavirus.htm.

Leon N, Surender R, Bobrow K, Muller J, and Farmer A. 2015. Improving treatment adherence for blood pressure lowering via mobile phone SMS-messages in South Africa: a qualitative evaluation of the SMS-text Adherence SuppoRt (StAR) trial. BMC Family Practice 16:80. 10.1186/s12875-015-0289-7 
503

504

505

506

507

508

509

510

511

512

513

514

515

516

517

518

519

520

521

522

523

524

525

526

527

528

529

530

531

532

533

534

535

536

537

538

539

540

541

542

543

544

545

546

547

548

549

550

551

552

Lloyd-Sherlock P, Beard J, Minicuci N, Ebrahim S, and Chatterji S. 2014. Hypertension among older adults in low- and middle-income countries: prevalence, awareness and control. International Journal of Epidemiology 43:116-128. 10.1093/ije/dyt215

MacKinnon AS. 2001. Of oxford bags and twirling canes: the state, popular responses, and Zulu antimalaria assistants in the early-twentieth-century Zululand malaria campaigns. Radic Hist Rev 80:76-100. 10.1215/01636545-2001-80-76

Maredza M, Bertram MY, Gomez-Olive XF, and Tollman SM. 2016. Burden of stroke attributable to selected lifestyle risk factors in rural South Africa. BMC Public Health 16:143. 10.1186/s12889-016-2805-7

Neal B, MacMahon S, Chapman N, and Blood Pressure Lowering Treatment Trialists C. 2000. Effects of ACE inhibitors, calcium antagonists, and other blood-pressure-lowering drugs: results of prospectively designed overviews of randomised trials. Blood Pressure Lowering Treatment Trialists' Collaboration. Lancet 356:1955-1964. 10.1016/s01406736(00)03307-9

Noubiap JJ, Nansseu JR, Nkeck JR, Nyaga UF, and Bigna JJ. 2018. Prevalence of white coat and masked hypertension in Africa: A systematic review and meta-analysis. Journal of Clinical Hypertension (Greenwich, Conn) 20:1165-1172. 10.1111/jch.13321

Nulu S, Aronow WS, and Frishman WH. 2016. Hypertension in Sub-Saharan Africa: A Contextual View of Patterns of Disease, Best Management, and Systems Issues. Cardiology in Review 24:30-40. 10.1097/CRD.0000000000000083

Organization WH. 2010. WHO STEPS instrument (core and expanded). The WHO STEPwise approach to noncommunicable disease risk factor surveillance Geneva: World Health Organization.

Peltzer K, and Phaswana-Mafuya N. 2013. Hypertension and associated factors in older adults in South Africa. Cardiovascular Journal of Africa 24:67-71. 10.5830/CVJA-2013-002

Perlman DC, Jordan AE, and Nash D. 2016. Conceptualizing Care Continua: Lessons from HIV, Hepatitis C Virus, Tuberculosis and Implications for the Development of Improved Care and Prevention Continua. Front Public Health 4:296. 10.3389/fpubh.2016.00296

Price AJ, Crampin AC, Amberbir A, Kayuni-Chihana N, Musicha C, Tafatatha T, Branson K, Lawlor DA, Mwaiyeghele E, Nkhwazi L, Smeeth L, Pearce N, Munthali E, Mwagomba BM, Mwansambo C, Glynn JR, Jaffar S, and Nyirenda M. 2018. Prevalence of obesity, hypertension, and diabetes, and cascade of care in sub-Saharan Africa: a crosssectional, population-based study in rural and urban Malawi. Lancet Diabetes Endocrinol 6:208-222. 10.1016/S2213-8587(17)30432-1

Release S, and P Á. 2019. Mid-year population estimates. Statistics South Africa, Pretoria[Cited 2013 May 14] Available from: http://www statssa gov za/publications/statsdownload asp.

Schneider H, Sanders D, Besada D, Daviaud E, and Rohde S. 2018. Ward-based primary health care outreach teams in South Africa: developments, challenges and future directions. South African health review 2018:59-65.

Seedat Y, Rayner B, and Veriava Y. 2014. South African hypertension practice guideline 2014. South African Journal of Diabetes and Vascular Disease 11:139-144.

Sharman M, and Bachmann M. 2019. Prevalence and health effects of communicable and noncommunicable disease comorbidity in rural KwaZulu-Natal, South Africa. Tropical Medicine and International Health 24:1198-1207. 10.1111/tmi.13297

Siedner MJ, Baisley K, Orne-Gliemann J, Pillay D, Koole O, Wong EB, Matthews P, Tanser F, Herbst K, Barnighausen T, and Bachmann M. 2018. Linkage to primary care after homebased blood pressure screening in rural KwaZulu-Natal, South Africa: a populationbased cohort study. BMJ Open 8:e023369. 10.1136/bmjopen-2018-023369

Ssentongo P, Ssentongo AE, Heilbrunn ES, Ba DM, and Chinchilli VM. 2020. Association of cardiovascular disease and 10 other pre-existing comorbidities with COVID-19 mortality:

Peer) reviewing PDF | (2021:05:60819:1:1:CHECK 2 Sep 2021) 
553

554

555

556

557

558

559

560

561

562

563

564

565

566

567

568

569

570

571

572

573

574

575

A systematic review and meta-analysis. PloS One 15:e0238215.

10.1371/journal.pone.0238215

Stats S. 2018. Men, women and children. Findings of the Living Conditions Survey, 2014/15.

Report No. 03-10-02 2014.

Steyn K, Bradshaw D, Norman R, and Laubscher R. 2008. Determinants and treatment of hypertension in South Africans: the first Demographic and Health Survey. South African Medical Journal 98:376-380.

Ware LJ, Chidumwa G, Charlton K, Schutte AE, and Kowal P. 2019. Predictors of hypertension awareness, treatment and control in South Africa: results from the WHO-SAGE population survey (Wave 2). Journal of Human Hypertension 33:157-166. 10.1038/s41371-018-0125-3

WHO. 2014. Global status report on noncommunicable diseases 2014: World Health Organization.

WHO. 2016. Global report on diabetes. Geneva: World Health Organization.

WHO. 2019. Hypertension. Available at https://www.who.int/news-room/factsheets/detail/hypertension.

WHO. 2020. WHO technical specifications for automated non-invasive blood pressure measuring devices with cuff.

Wong EB, Olivier S, Gunda R, Koole O, Surujdeen A, Gareta D, Munatsi D, Modise TH, Dreyer J, and Nxumalo S. 2021. Convergence of infectious and non-communicable disease epidemics in rural South Africa: a cross-sectional, population-based multimorbidity study. The Lancet Global Health 9:e967-e976. 


\section{Table 1 (on next page)}

Socio-demographic and clinical characteristics of adult participants diagnosed with hypertension in the Ingwavuma rural community ( $N=131$ 


\begin{tabular}{|c|c|c|c|c|}
\hline \multicolumn{2}{|c|}{ Variables and categories } & Female n (\%) & Male n (\%) & Total n (\%) \\
\hline \multicolumn{2}{|l|}{ Overall } & $89(67.9)$ & $42(32.1)$ & $131(100)$ \\
\hline \multirow[t]{3}{*}{ Age group } & $18-40$ years & $18(20.2)$ & $5(11.9)$ & $23(17.6)$ \\
\hline & $40-59$ years & $35(39.3)$ & $17(40.5)$ & $52(39.7)$ \\
\hline & $>=60$ years & $36(40.4)$ & $20(47.6)$ & $56(42.7)$ \\
\hline \multirow{3}{*}{$\begin{array}{l}\text { Education } \\
\text { level }\end{array}$} & None & $59(66.3)$ & $19(45.2)$ & $78(59.5)$ \\
\hline & Primary & $17(19.1)$ & $14(33.3)$ & $31(23.7)$ \\
\hline & Post-primary & $13(14.6)$ & $9(21.4)$ & $22(16.8)$ \\
\hline \multirow{3}{*}{$\begin{array}{l}\text { Marital } \\
\text { status }\end{array}$} & Single & $56(62.9)$ & $17(40.5)$ & $73(55.7)$ \\
\hline & Married & $12(13.5)$ & $9(21.4)$ & $21(16.0)$ \\
\hline & Cohabiting & $21(23.6)$ & $16(38.1)$ & $37(28.2)$ \\
\hline \multirow{2}{*}{$\begin{array}{l}\text { Occupational } \\
\text { status }\end{array}$} & Unemployed & $86(96.4)$ & $37(88.1)$ & $123(93.9)$ \\
\hline & Employed & $3(3.4)$ & $5(11.9)$ & $8(6.1)$ \\
\hline \multirow{3}{*}{$\begin{array}{l}\text { Body mass } \\
\text { index }\end{array}$} & Up to normal weight & $27(30.3)$ & $20(47.6)$ & $47(35.9)$ \\
\hline & Overweight & $33(37.1)$ & $14(33.3)$ & $47(35.9)$ \\
\hline & Obese & $29(32.6)$ & $8(19.0)$ & $37(28.2)$ \\
\hline \multirow{2}{*}{ Diabetes } & No & $51(57.3)$ & $25(59.5)$ & $76(58.0)$ \\
\hline & Yes & $38(42.7)$ & $17(40.5)$ & $55(42.0)$ \\
\hline \multirow{3}{*}{$\begin{array}{l}\text { Physical } \\
\text { activity level }\end{array}$} & Insufficient & $17(19.1)$ & $5(11.9)$ & $22(16.8)$ \\
\hline & Sufficient & $19(21.3)$ & $4(9.5)$ & $23(17.6)$ \\
\hline & High & $53(59.6)$ & $33(78.6)$ & $86(65.6)$ \\
\hline \multirow{2}{*}{$\begin{array}{l}\text { Alcohol } \\
\text { consumption }\end{array}$} & No & $77(86.5)$ & $27(64.3)$ & $104(79.4)$ \\
\hline & Yes & $12(13.5)$ & $15(35.7)$ & $27(20.6)$ \\
\hline \multirow[t]{2}{*}{ Tobacco use } & No & $87(97.8)$ & $34(81.0)$ & $121(92.4)$ \\
\hline & Yes & $2(2.2)$ & $8(19.0)$ & $10(7.6)$ \\
\hline
\end{tabular}

1

2

3

4

5 


\section{Table 2 (on next page)}

Levels and association of hypertension screening, awareness, treatment and control across socio-demographic factors in the Ingwavuma rural community

Note: ${ }^{a}$ Cramer's V effect size for significant variables, ${ }^{b}$ Statistically significant categories after Holm and Holm-Bonferonni corrections. Bold p-values indicate significant statistically variable. 
1

\begin{tabular}{|c|c|c|c|c|c|c|c|c|c|}
\hline \multicolumn{2}{|l|}{ Variable } & $\begin{array}{l}\text { Screened } \\
\text { n (\%) }\end{array}$ & $\begin{array}{l}P \text { Value } \\
(E S)^{\mathrm{a}}\end{array}$ & $\begin{array}{l}\text { Diagnosed } \\
\text { n (\%) }\end{array}$ & $\begin{array}{l}P \text { Value } \\
\left(\text { ES) }{ }^{\mathrm{a}}\right.\end{array}$ & $\begin{array}{l}\text { Treated } \\
\text { n (\%) }\end{array}$ & $P$ Value & $\begin{array}{l}\text { Controlled } \\
\text { n (\%) }\end{array}$ & $P$ Value \\
\hline \multirow{2}{*}{ Gender } & Female & $80(89.9)$ & \multirow[t]{2}{*}{0.285} & $57(71.3)$ & \multirow{2}{*}{0.772} & $51(89.5)$ & \multirow{2}{*}{0.443} & $26(53.1)$ & \multirow{2}{*}{0.173} \\
\hline & Male & 35 (85.3) & & 24 (68.6) & & $20(83.3)$ & & $7(35.0)$ & \\
\hline \multirow{3}{*}{ Age group } & $18-39$ & $18(73.8)$ & \multirow{3}{*}{0.186} & $10(55.6)$ & \multirow{3}{*}{0.287} & $7(70.0)$ & \multirow{3}{*}{0.095} & $3(42.9)$ & \multirow{3}{*}{0.203} \\
\hline & $40-59$ & $45(86.5)$ & & $34(75.6)$ & & $29(85.3)$ & & $17(60.7)$ & \\
\hline & $60+$ years & $52(92.9)$ & & $37(71.2)$ & & $35(94.6)$ & & $13(38.2)$ & \\
\hline \multirow{3}{*}{$\begin{array}{l}\text { Formal } \\
\text { education } \\
\text { level }\end{array}$} & None & $70(89.7)$ & \multirow{3}{*}{0.053} & $55(78.6)$ & \multirow{3}{*}{0.41} & $51(92.7)$ & \multirow{3}{*}{0.128} & $22(44.9)$ & \multirow{3}{*}{0.334} \\
\hline & Primary & $29(93.5)$ & & $18(62.1)$ & & $14(77.8)$ & & $9(64.3)$ & \\
\hline & Post-primary & $16(72.7)$ & & $8(50.0)$ & & $6(75.0)$ & & $2(33.3)$ & \\
\hline \multirow{3}{*}{$\begin{array}{l}\text { Marital } \\
\text { status }\end{array}$} & Not married & $67(91.8)$ & \multirow{3}{*}{0.118} & $45(67.2)$ & \multirow{3}{*}{0.136} & $38(84.1)$ & \multirow{3}{*}{0.518} & $17(45.9)$ & \multirow{3}{*}{0.733} \\
\hline & Married & $19(90.5)$ & & $17(89.5)$ & & $15(88.2)$ & & $8(57.1)$ & \\
\hline & Cohabiting & $29(78.4)$ & & $19(65.5)$ & & $18(94.7)$ & & $8(24.2)$ & \\
\hline \multirow{2}{*}{$\begin{array}{l}\text { Employment } \\
\text { status }\end{array}$} & Unemployed & $110(89.4)$ & \multirow{2}{*}{$\begin{array}{c}\mathbf{0 . 0 2 4} \\
(0.197)\end{array}$} & $78(70.9)$ & \multirow[t]{2}{*}{0.631} & $69(88.5)$ & \multirow{2}{*}{0.330} & $32(47.8)$ & \multirow{2}{*}{0.950} \\
\hline & Employed & $5(62.5)$ & & $3(60.0)$ & & $2(66.7)$ & & $1(50.0)$ & \\
\hline \multirow{2}{*}{$\begin{array}{l}\text { Diabetes } \\
\text { mellitus }\end{array}$} & No & $66(88.8)$ & \multirow{2}{*}{0.698} & $50(75.8)$ & \multirow{2}{*}{0.147} & $44(88.0)$ & \multirow{2}{*}{0.904} & $22(50.0)$ & \multirow{2}{*}{0.632} \\
\hline & Yes & $49(89.1)$ & & $31(63.3)$ & & $27(87.1)$ & & $11(44.0)$ & \\
\hline & Normal weight & $41(87.2)$ & & $29(70.7)$ & & $26(89.6)$ & & $13(50.0)$ & \\
\hline Body mass & Overweight & $41(87.2)$ & 0.954 & $22(53.6)^{b}$ & $\begin{array}{l}\mathbf{0 . 0 0 2} \\
(0326)\end{array}$ & $18(81.8)$ & 0.621 & $8(50.0)$ & 0.903 \\
\hline & Obese & $33(89.1)$ & & $30(90.9)^{b}$ & & $27(90.0)$ & & $12(44.4)$ & \\
\hline & Low & $18(81.8)$ & & $16(88.9)$ & & $13(81.3)$ & & $5(38.5)$ & \\
\hline $\begin{array}{l}\text { Physical } \\
\text { activity level }\end{array}$ & Sufficient & $22(95.7)$ & 0.353 & $12(54.5)$ & 0.06 & $11(91.7)$ & 0.658 & $5(50.0)$ & 0.755 \\
\hline & High & $75(87.2)$ & & $53(70.7)$ & & $47(88.7)$ & & $23(50.0)$ & \\
\hline Alcohol & No & $93(89.4)$ & 0261 & $66(71.0)$ & 0.797 & $60(90.9)$ & 006 & 27 (46.6) & 162 \\
\hline consumption & Yes & $22(81.5)$ & 0.201 & $15(68.2)$ & 0.191 & $11(73.3)$ & 0.002 & $6(54.5)$ & 0.027 \\
\hline T & No & $107(88.4)$ & 0.434 & $75(70.1)$ & 0769 & $66(88.0)$ & 0738 & $32(50.0)$ & 0359 \\
\hline & Yes & $8(80.0)$ & & $6(75.0)$ & & $5(83.3)$ & & $1(20.0)$ & \\
\hline
\end{tabular}

2 


\section{Table 3 (on next page)}

Unadjusted and adjusted logistic regression analysis on hypertension screening prevalence among adults in the Ingwavuma rural community

Note: ${ }^{1} \mathrm{COR}$ : Crude odds ratio, ${ }^{2} \mathrm{AOR}$ : Adjusted odds ratio. Bold p-values indicate significant statistically variables 
1

\begin{tabular}{|c|c|c|c|c|c|}
\hline \multicolumn{2}{|l|}{ Variable } & \multirow{2}{*}{$\begin{array}{l}\mathbf{C O R}^{1}(\mathbf{9 5 \%} \mathbf{C I}) \\
\text { Reference }\end{array}$} & \multirow[t]{2}{*}{$P$ Value } & \multirow[t]{2}{*}{$\mathrm{AOR}^{2}(95 \% \mathrm{CI})$} & \multirow[t]{2}{*}{$P$ Valuc } \\
\hline \multirow[t]{2}{*}{ Gender } & Female & & & & \\
\hline & Male & $0.563(0.194-1.631)$ & 0.289 & $1.272(0.242-6.698)$ & 0.776 \\
\hline \multirow[t]{3}{*}{ Age group } & $18-39$ & Reference & & & \\
\hline & $40-59$ & $0.277(0.067-1.145)$ & 0.076 & $0.199(0.199-9.414)$ & 0.750 \\
\hline & $60+$ years & $0.495(0.136-1.799)$ & 0.285 & $0.493(0.493-32.302)$ & 0.194 \\
\hline \multirow{3}{*}{$\begin{array}{l}\text { Formal education } \\
\text { level }\end{array}$} & None & Reference & & & \\
\hline & Primary & $1.657(0.332-8.280)$ & 0.538 & $1.288(0.183-9.039)$ & 0.799 \\
\hline & Post-primary & $0.305(0.093-1.001)$ & 0.050 & $0.399(0.060-2.630)$ & 0.339 \\
\hline \multirow[t]{3}{*}{\begin{tabular}{|l|} 
Marital status \\
\end{tabular}} & Not married & Reference & & & \\
\hline & Married & $0.851(0.159-4.562)$ & 0.850 & $0.670(0.079-5.688)$ & 0.714 \\
\hline & Cohabiting & $0.325(0.103-1.020)$ & 0.054 & $0.126(0.025-0.629)$ & 0.011 \\
\hline \multirow[t]{2}{*}{ Employment } & Unemployed & Reference & & & \\
\hline & Employed & $0.197(0.042-0.921)$ & 0.039 & $0.129(0.017-0.952)$ & 0.045 \\
\hline \multirow[t]{2}{*}{\begin{tabular}{|l|} 
Diabetes mellitus \\
\end{tabular}} & No & Reference & & & \\
\hline & Yes & $1.237(0.421-3.635)$ & 0.698 & $1.907(0.439-8.280)$ & 0.389 \\
\hline \multirow[t]{3}{*}{\begin{tabular}{|l|} 
Body mass index \\
\end{tabular}} & Up to normal weight & Reference & & & \\
\hline & Overweight & $1.000(0.298-3.359)$ & 1.000 & $1.390(0.231-8.368)$ & 0.719 \\
\hline & Obese & $1.207(0.314-4.637)$ & 0.784 & $2.665(0.437-16.239)$ & 0.288 \\
\hline \multirow{3}{*}{$\begin{array}{l}\text { Physical activity } \\
\text { level }\end{array}$} & Low & Reference & & & \\
\hline & Sufficient & $4.889(0.501-47.708)$ & 0.172 & $8.173(0.576-115.941)$ & 0.121 \\
\hline & High & $1.515(0.432-5.313)$ & 0.516 & $2.589(0.526-12.752)$ & 0.242 \\
\hline \multirow{2}{*}{$\begin{array}{l}\text { Alcohol } \\
\text { consumption }\end{array}$} & No & Reference & & & \\
\hline & Yes & $0.520(0.164-1.651)$ & 0.268 & $0.284(0.061-1.318)$ & 0.108 \\
\hline \multirow[t]{2}{*}{ Tobacco smoking } & No & Reference & & & \\
\hline & Yes & $0.523(0.101-2.716)$ & 0.441 & $1.023(0.120-8.750)$ & 0.983 \\
\hline
\end{tabular}




\section{Table 4 (on next page)}

Gender stratified adjusted logistic regression analysis on hypertension screening prevalence among adults in the Ingwavuma rural community

Note: Bold p-values indicate significant statistically variables 
1

\begin{tabular}{|c|c|c|c|}
\hline \multirow{2}{*}{\multicolumn{2}{|c|}{ Variable }} & \multicolumn{2}{|c|}{$P$ Value } \\
\hline & & \multirow{2}{*}{ Female } & \multirow{2}{*}{ Male } \\
\hline \multirow{3}{*}{ Age group } & 18-39 & & \\
\hline & $40-59$ & 0.076 & 0.750 \\
\hline & $60+$ years & 0.285 & 0.194 \\
\hline \multirow[t]{3}{*}{ Formal education level } & None & & \\
\hline & Primary & 0.538 & 0.799 \\
\hline & Post-primary & 0.050 & 0.339 \\
\hline \multirow[t]{3}{*}{ Marital status } & Not married & & \\
\hline & Married & 0.850 & 0.714 \\
\hline & Cohabiting & 0.011 & 0.054 \\
\hline \multirow[t]{2}{*}{ Employment } & Unemployed & & \\
\hline & Employed & 0.039 & 0.045 \\
\hline \multirow[t]{2}{*}{\begin{tabular}{|l|} 
Diabetes mellitus \\
\end{tabular}} & No & & \\
\hline & Yes & 0.698 & 0.389 \\
\hline \multirow[t]{3}{*}{ Body mass index } & Up to normal weight & & \\
\hline & Overweight & 1.000 & 0.719 \\
\hline & Obese & 0.784 & 0.288 \\
\hline \multirow[t]{3}{*}{\begin{tabular}{|l|} 
Physical activity level \\
\end{tabular}} & Low & & \\
\hline & Sufficient & 0.172 & 0.121 \\
\hline & High & 0.516 & 0.242 \\
\hline \multirow[t]{2}{*}{\begin{tabular}{|l|} 
Alcohol consumption \\
\end{tabular}} & No & & \\
\hline & Yes & 0.268 & 0.108 \\
\hline \multirow[t]{2}{*}{\begin{tabular}{|l|} 
Tobacco smoking \\
\end{tabular}} & No & & \\
\hline & Yes & 0.441 & 0.983 \\
\hline
\end{tabular}


Figure 1

Map of South Africa showing Ingwavuma rural community in north-eastern KwaZuluNatal

Map data $\odot 2021$ Google 


Figure 2

Study sampling scheme

Subscripts refer to randomly sampled household blocks in wards indicated by the index numbers

\begin{tabular}{|c|c|c|c|c|c|c|}
\hline \multicolumn{6}{|c|}{ Convenience sampling of study area } & Totals \\
\hline \multicolumn{2}{|c|}{ Ward 13} & & & \multicolumn{2}{|c|}{ Ward 17} & \multirow[t]{2}{*}{3 wards } \\
\hline \multicolumn{6}{|c|}{ Random sampling of community health blocks within wards } & \\
\hline Block $13_{1}$ & Block $13_{2}$ & Block $16_{1}$ & Block $16_{2}$ & Block $17_{1}$ & Block $17_{2}$ & \multirow{3}{*}{$\begin{array}{c}6 \text { blocks } \\
264 \\
\text { households }\end{array}$} \\
\hline \multicolumn{6}{|c|}{ Systematic random sampling of households from block listing } & \\
\hline Block $13_{1}=41$ & Block $13_{2}=44$ & Block $16_{1}=49$ & Block $16_{2}=42$ & Block $17_{1}=45$ & Block $17_{2}=43$ & \\
\hline \multicolumn{6}{|c|}{ Random sampling of participants with gender stratified lottery for households with more than 2 consenting participants } & \multirow{2}{*}{$\begin{array}{c}400 \\
\text { participants }\end{array}$} \\
\hline Block $13_{1}=66$ & Block $13_{2}=67$ & Block $16_{1}=67$ & Block $16_{2}=67$ & Block $17_{1}=66$ & Block $17_{2}=67$ & \\
\hline
\end{tabular}


Figure 3

The hypertension cascade of care

Note: Elbow arrow connectors (a) denote step-wise progression in the hypertension care cascade. Dashed arrows (b) depict step-wise attrition along the hypertension care cascade 


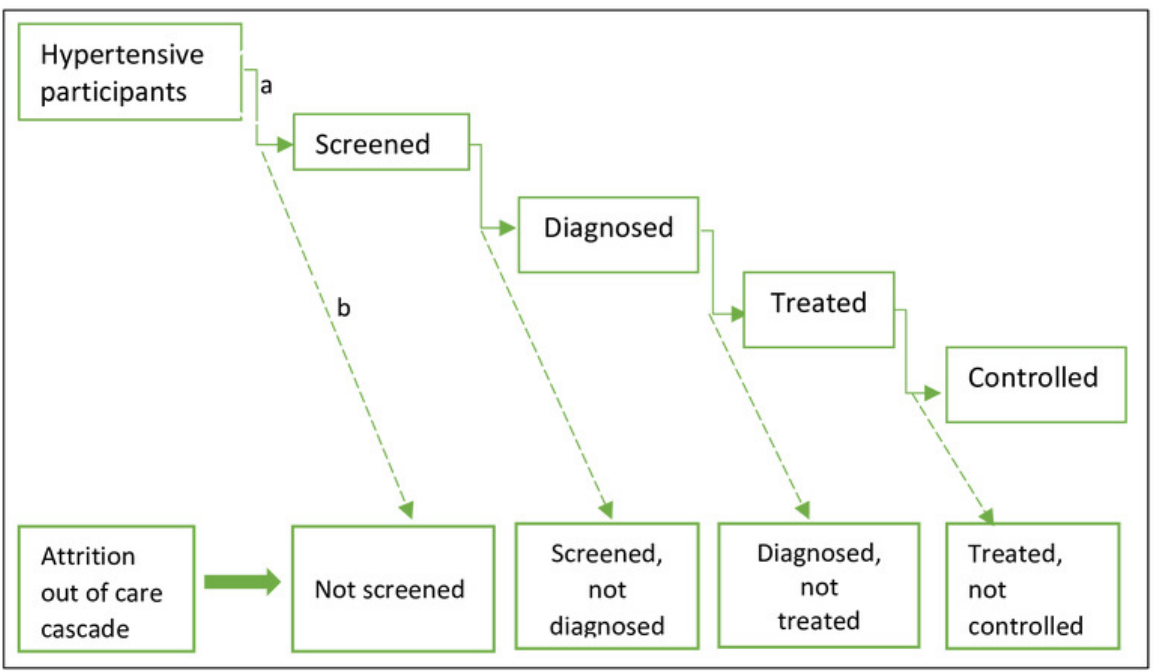




\section{Figure 4}

Number of people at various hypertension care cascade stages out of a sample of 131 participants

Note: (a) Overall gap comprising of hypertensive participants who had not been screened. (b) Overall gap of hypertensive participants not aware of their hypertensive condition. (c) Overall gap of hypertensive participants not under pharmacological treatment for hypertension. (d) Overall gap of hypertensive participants with uncontrolled hypertension 


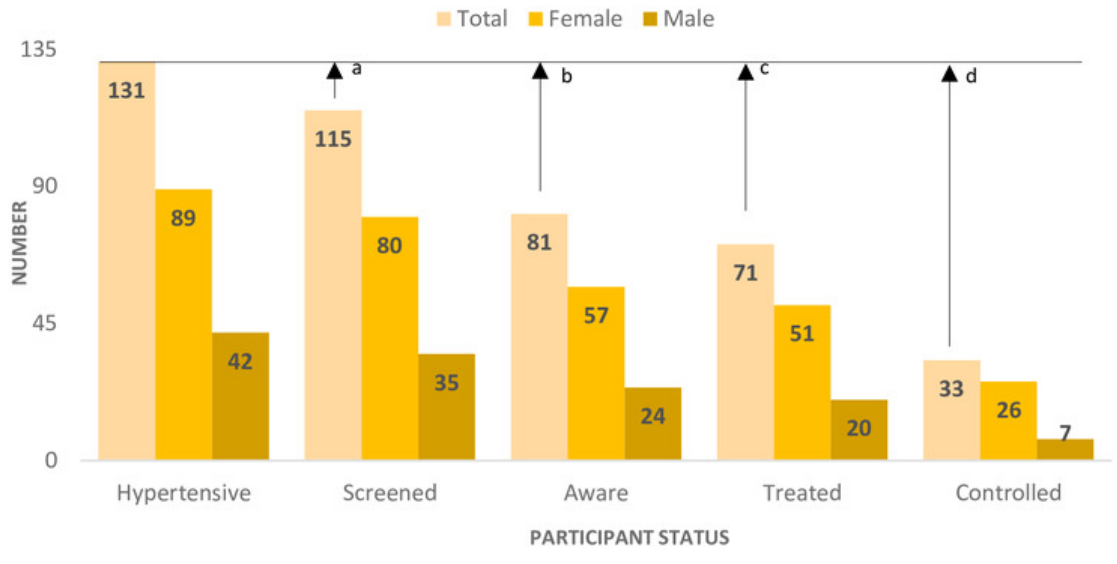


Figure 5

Hypertension cascade of care showing progression rates and coverage gaps in the Ingwavuma community as proportions of the subsample $(\mathrm{N}=131)$. 


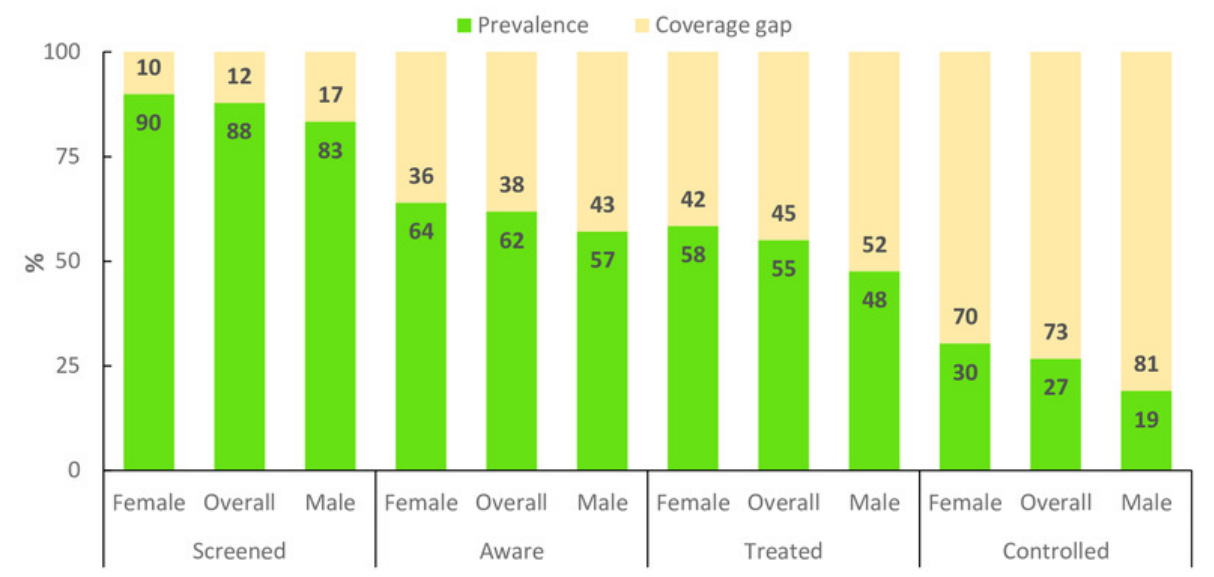


Figure 6

Hypertension cascade of care showing stage-by-stage progression rates and coverage gaps in the Ingwavuma community 


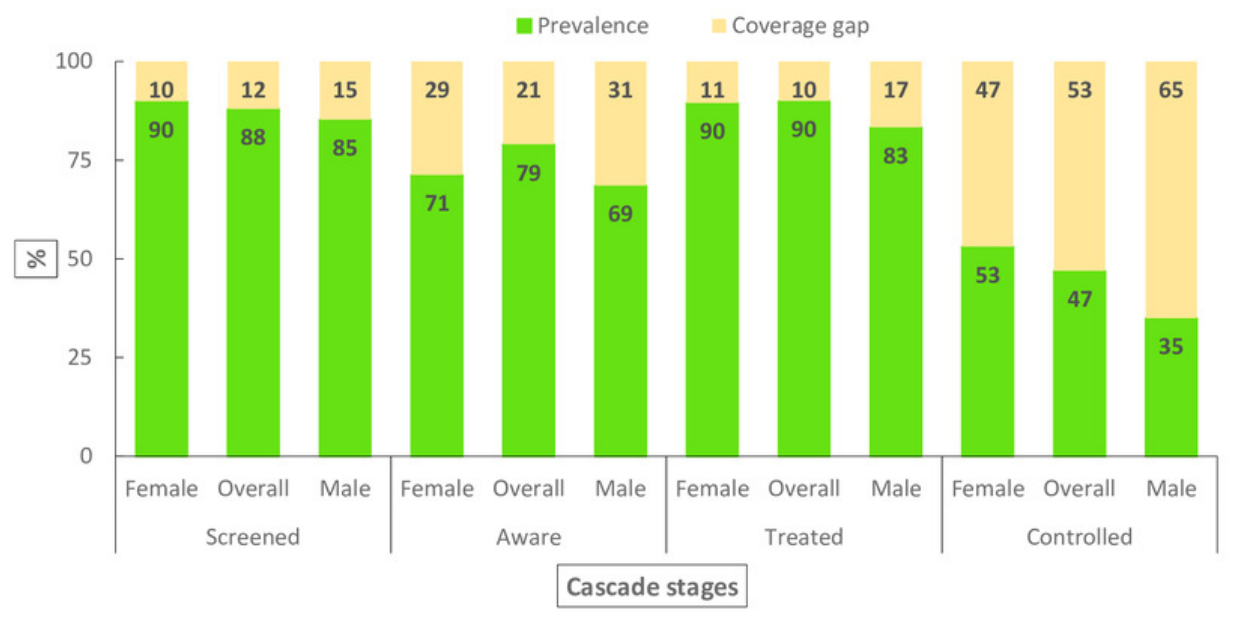

